\title{
La transversalidad de la obra de Manuel Zapata Olivella en el currículum de la Cátedra de Estudios Afrocolombianos*
}

\author{
Alejandra Rengifo M. ${ }^{1}$ \\ Central Michigan University \\ ORCID: 0000-0002-8232-5815 \\ Recibido: 13 de diciembre de 2019 \\ Aceptado: 20 de febrero de 2020
}

\section{RESUMEN}

Este artículo presenta algunas de las limitantes por las cuales la Cátedra de Estudios Afrocolombianos no ha podido tener una implementación adecuada en el currículo de la Etnoeducación colombiana a la vez que propone la transversalidad de la obra de Manuel Zapata Olivella como una posible solución.

Palabras claves: transversalidad, Cátedra de estudios afrocolombianos, etnoeducación, Manuel Zapata Olivella.

\begin{abstract}
This article presents some of the limitations the Cátedra de Estudios Afrocolombianos has had to be implemented 8within the Ethnic education curriculum while it proposes that the transversality of the works of Manuel Zapata Olivella could be a solution.
\end{abstract}

Keywords: transversality, Cátedra de Estudios Afrocolombianos, Ethnic education, Manuel Zapata Olivella.

La educación en cualquier nación es el eje que erige y sostiene su sociedad, su cultura. Cada país conforma su sistema educativo según los contextos históricos, sociales, culturales y económicos a los que esté sujeto. Colombia no es la excepción y si bien siempre se ha debatido la calidad de la educación en el país se debe resaltar que desde 1991 hasta 1994 se expidieron distintas leyes respecto a la educación nacional que cambiaron el panorama educativo y social, no solo para los colombianos en general sino también para las comunidades étnicas ${ }^{2}$. Estas leyes intentan hacer un cambio estructural en una entidad que desde su incepción no había incluido a renglones poblacionales

\footnotetext{
*The Transversality of the Works of Manuel Zapata Olivella in the Curricula of Afro Colombian Studies Courses

${ }^{1}$ Doctora en Literatura en español, Profesora titular de Español y Estudios globales y culturales del Department of World Languages and Cultures, de la Central Michigan University. Correo: rengi1a@cmich.edu.

${ }^{2}$ En 1991 la nueva Constitución en su artículo 7 reconoce y protege la diversidad étnica y cultural del país, en 1993 se expide la Ley 70 que protege, entre otras cosas, la identidad cultural de las comunidades negras y finalmente en 1994 con la Ley 115 se ordena la organización del Sistema Educativo General Colombiano estableciendo "normas generales para regular el Servicio Público de la Educación que cumple una función social acorde con las necesidades e intereses de las personas, de la familia y de la sociedad" (Ministerio de Educación, s.f.)
} 
claves para la sociedad colombiana como los indígenas, los afrodescendientes, los raizales y los rom. De esta época data el interés del Ministerio de Educación Nacional por apoyar y promover la educación para grupos étnicos a través del programa de Etnoeducación. Este programa abre "las puertas para que los diversos pueblos logren una autonomía que les permita, entre otras, proponer modelos de educación propia acordes con su forma de vida" (Ministerio de Educación, s.f.). Es así como la Etnoeducación permitió posteriormente la creación de la Cátedra de Estudios Afrocolombianos (en adelante la CEA) en la cual los afrodescendientes podrían plantear contenidos que enseñara sobre su historia, su cultura, su idiosincrasia, sus costumbres, su cosmovisión al resto de la población colombiana.

Sin embargo, la CEA, desde su concepción, ha tenido limitantes en su implementación para poder producir los cambios necesarios en el currículo educativo nacional porque no ha hecho uso de figuras reconocidas pertenecientes a la comunidad que representa para darle un empuje a su ejecución. Una cátedra donde se resalta una comunidad étnica supone hacer uso de todos los recursos disponibles (literatura, arte, música, cultura) para mostrar lo que ella ha logrado y lo que desea seguir construyendo en el futuro. Este es el caso de la ausencia de la obra de Manuel Zapata Olivella en el currículo de la CEA. El interés de este artículo es mostrar cómo la transversalidad de la obra de Zapata Olivella sería un beneficio invaluable para ayudar a cumplir con la norma a la cual está sujeta la CEA y también para fortalecerla y hacer posible su cumplimiento. Para lograr este cometido se hace necesario una descripción de la historia de la CEA, su concepción y actuales limitantes para su implementación al igual que estudiar, someramente, la obra de Zapata Olivella para ver la transversalidad que esta tiene para dinamizar la CEA.

\section{Cátedra de Estudios Afrocolombianos (CEA)}

A partir de la nueva Constitución de 1991 el estado colombiano oficialmente establece, reconoce y protege la diversidad étnica y cultural de la nación. En un intento por empezar a crear un proyecto de nación pluriétnico, empieza a trabajar en la creación, por medio de la educación, de un plan en el cual se considera a los indígenas, afrodescendientes, raizales y gitanos como sujetos de derecho, siendo

la política pública de etnoeducación (de la cual hace parte la CEA) [...], la política de Estado orientada a dar respuesta a las demandas de las poblaciones afrodescendientes e indígenas en el campo educativo; a lo cual se podría añadir que estas políticas educativas han sido comprendidas como la manera de tramitar, por la vía educativa, el reconocimiento constitucional de la multiculturalidad del país (Rojas, 2008: 27).

Por tanto, esa es la protección y reconocimiento del Estado a estas comunidades, por medio de la educación, el pensar que bajo esta figura se visibilice a estas minorías y se reconozcan sus aportes a la diversidad cultural del país. Uno de los objetivos principales es lograr una activa participación en los estamentos estatales de estas minorías, siendo una de las metas finales el acceso a la educación en todos los niveles. Es de esta manera que la CEA surge como una idea de creación 
de una cátedra con lineamientos curriculares para "[fijar] orientaciones teóricas y metodológicas para entender de una forma crítica, profunda e intercultural temáticas y contenidos relacionados con los legados socioculturales de las comunidades negras en el marco de la historia del Mundo, América y Colombia” (Ibagón Martín, 2015: 15). Es más, la CEA en sí “surge como resultado de la reglamentación de la Ley 70 de 1993, conocida como Ley de comunidades negras, y la Ley 115 de 1994 o Ley general de educación" (Rojas, 2008: 29), y es de cumplimiento obligatorio en todos los establecimientos privados y públicos del país a partir del decreto 1122 de 1998. Es una cátedra que “debe afectar el currículo, ya sea de manera integral en el área de Ciencias Sociales, o mediante proyectos pedagógicos que afecten el plan de estudios. Esto es, en su concepción original, Cátedra no es equivalente a una asignatura o materia aislada" (30). Se hace la salvedad que la Cátedra no es exclusivamente de y para los afrodescendientes, porque "no es una 'cátedra' en el sentido convencional, es decir, no es una asignatura más en el plan de estudios, es un proyecto complejo que debería afectar el conjunto del Proyecto Educativo Institucional” (31) y con ella se busca

generar procesos pedagógicos orientados al conocimiento y reconocimiento de estas poblaciones y sus aportes históricos y presentes a la construcción de la Nación, al tiempo que se generan mecanismos para la erradicación del racismo que históricamente han padecido. Es decir, la Cátedra promueve la construcción de estrategias pedagógicas para transformar las relaciones de toda la sociedad colombiana en relación con las poblaciones afrodescendientes. (30)

Una legislación significativa para la comunidad afrodescendiente. Sin embargo, con la

formulación de la ley general de educación en el año 1994, se produjo una reorganización del sistema educativo colombiano en la que la política de descentralización se constituyó en uno de sus pilares. Con ésta, se reasignaron funciones a nivel del aparato institucional, dando mayor autonomía a los entes territoriales en la definición de la destinación de recursos al sector educativo. En consecuencia, el Ministerio de Educación Nacional (MEN) perdió la centralidad que previamente tenía, aumentándose por el contrario el poder de injerencia de las secretarias de educación departamentales y municipales. (Ibagón Martín, 2015: 17)

Es de esta manera que esta formulación permite darles autonomía a las secretarías de educación departamentales y municipales para aplicar las leyes 70 y 115 y es donde emergen las limitantes para que la CEA pueda formar parte indiscutible del pensum de ciencias sociales en el país. Por consiguiente, como la obligatoriedad de la CEA "no es un capricho de los afrodescendientes, es una condición fundamental para que se cumpla su propósito" (Rojas, 2008: 30), porque lo que se propone con ella es apoyar "la redefinición y transformación de las relaciones interculturales en el conjunto de la sociedad [...] no tiene sentido dirigirlo solo a uno de los sectores que participa de la relación” (30). También se debe aclarar que la CEA forma parte de la etnoeducación porque desde

el punto de vista pedagógico y normativo, la relación entre etnoeducación y Cátedra es de complementariedad. De hecho, la Cátedra hace parte de los desarrollos de la política etnoeducativa y de los derechos educativos de los grupos étnicos, en particular el afrocolombiano, tal como lo establecen sus lineamientos curriculares. (MEN en Rojas, 2008: 33) 
Por otro lado, un aspecto interesante de la norma de la Cátedra es el que dice que el "ejercicio de inserción de contenidos temáticos afrocolombianos por áreas y niveles educativos lo deben hacer los propios maestros, considerando las realidades particulares regionales y de las instituciones escolares" (MEN en Rojas, 2008: 31). Es así como son importantes los resultados del estudio investigativo hecho en 2010 en Bogotá por Nilson Ibagón Martín sobre la implementación de la Cátedra pues "aún [se] está lejos de indicadores reales de efectiva operativización y cambio curricular en esta materia" (17). Estos resultados muestran que varias de las instituciones que han cumplido con el requisito de intentar tener una malla curricular para la CEA son precisamente aquellas que educan a estudiantes de esta minoría y/o de clase social trabajadora. También se puede ver que una de las limitantes de la CEA es que

se configura por parte de los agentes educativos una visión jerárquica desde la que se da una valoración diferenciada de las normativas curriculares, proceso en el que el marco legal y pedagógico de la CEA, es entendido como inferior frente a otras leyes y disposiciones curriculares. (Ibragón Martín, 2015: 16)

Situación, esta, que dificulta la feliz ejecución de una Cátedra creada como parte de un macroproyecto educativo nacional. A su vez, es decisivo que la inserción de contenidos debe ser hecha por los mismos maestros. La inclusión de autores, ejes temáticos y contenidos es a discreción del plantel escolar y de aquellos que enseñan la materia, por ende, cuando hay falencias en el contenido, como por ejemplo no incluir autores claves que aportan con su obra al estudio histórico y social de las distintas comunidades, y en este caso en particular la afrodescendiente, el propósito de la Cátedra pierde su importancia. La lista de posibles autores afrodescendientes para estudiar puede pensarse extensa, no obstante Manuel Zapata Olivella es tal vez el escritor afrodescendiente más representativo de esta comunidad y el que mejor pudo exponerla.

\section{Manuel Zapata Olivella: breve sinopsis de su obra}

La muerte de Manuel Zapata Olivella en 2004 dejó un vacío en las letras colombianas. Nacido en Lorica, Córdoba, en 1920, este escritor, médico, antropólogo, folclorista y activista social fue uno de los más altos exponentes y voceros de la cultura afrocolombiana. Su obra ${ }^{3}$ incluye textos que van desde la novela histórica a la de denuncia, pasando por los estudios antropológicos y folcloristas. Su género fue el de la novela sin dejar de lado el ensayo, los cuentos, el teatro y los estudios investigativos. En su obra delineó tanto la identidad como el imaginario de la diáspora africana, en particular en Colombia; publicó su primera novela en 1942 y continuó escribiendo y publicando hasta poco antes de morir en 2004. En los años setenta fue descubierto por académicos estadounidenses y desde ese momento este autor ha sido más estudiado, reconocido y laureado en el extranjero que en su propio país y

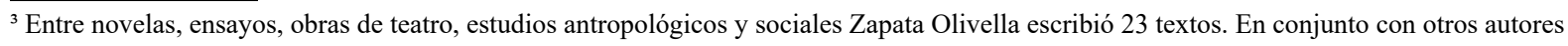
publicó cuatro colecciones. 
[se] le valida como escritor e intelectual dentro del contexto de la academia colombiana, la cual no se ha decidido a incluirlo en los planes de estudio -en el canon, si se quiere-, como lo solicitaban desde los años setenta y ochenta investigadores como Richard L. Jackson en sus textos The Black Image in Latin American Literature (1976) y Black Writers in Latin America (1979), y Marvin A. Lewis en su Treading the Ebony Path: Ideology and Violence in Contemporary Afro-Colombian Prose Fiction (1987) (Palacios Palacios, 2018: 119).

Es precisamente a partir de esta época que estos mismos académicos empezaron a hablar de un campo de estudio afrohispanoamericano del cual Zapata Olivella eventualmente sería figura clave. Cierto, en la parte hispana del continente no se tenía concepción del tema, pero eventualmente la idea se naturalizó y fueron muchos de ellos los que allanaron el terreno para la eventual creación de los estudios afrolatinoamericanos en Estados Unidos llevando el concepto a universidades y programas en América Latina. En Colombia, posteriormente, se adoptó la idea y se empezó a hablar de literatura afrocolombiana, pero, aunque "el término 'afrocolombiano/a' comienza a usarse en Colombia por la década del cincuenta del siglo XX con el inicio de los estudios antropológicos, apenas en el siglo XXI se instala en el discurso literario del ámbito académico nacional” (Valero, 2013a: 16).

Discurso literario del cual Zapata Olivella fue uno de sus autores primigenios. Su intención: dar a conocer la cultura y la sociedad negra colombiana a la vez que denunciar su subyugación, negación, marginalización y olvido por parte del gobierno. Es así como Zapata Olivella se convirtió en el referente a seguir respecto del conocimiento de la diáspora africana en los círculos académicos universitarios en Colombia y América Latina.

Sucede entonces que la obra de Zapata Olivella se nutre tanto de la historia negra ${ }^{4}$ de Colombia como de la latinoamericana. La comunidad que Zapata Olivella expone y exalta es aquella que por décadas ha vivido rezagada de muchas maneras, la que desde un principio ha tenido obstáculos para poder pertenecer y tener derecho a lo público y a lo privado en la sociedad colombiana. Los textos de Zapata Olivella van más allá de querer hablar sobre los negros de Colombia a los negros de Colombia y esto es “¡Craso prejuicio! [Porque] él fue un gran escritor, un novelista, un investigador, un enciclopedista" (26) como aduce Mina Aragón en su artículo "Manuel Zapata Olivella: escritor y humanista" (2006). Su obra llena un vacío en las letras, cultura y sociedad colombiana sobre las contribuciones y la historia de los afrocolombianos. Fue prolífica y variada más no es uno de los bastiones de la literatura colombiana, como lo es García Márquez, ni siquiera después que se le incluyera en la Biblioteca de literatura afrocolombiana ${ }^{5}$.

\footnotetext{
${ }^{4}$ Para más información sobre la historia negra colombiana se puede consultar la obra de autores como Nina S. Friedemman, Jaime Arocha, Adriana Maya, Mauricio Pardo, Mauricio Archilla, entre muchos.

${ }^{5}$ Esta es una colección de 18 volúmenes y un ensayo de escritores afrocolombianos destacados en los últimos 150 años. Fue hecha en 2010 con el propósito de visibilizar y reconocer las contribuciones de autores afrocolombianos/as por medio de los "procesos de resistencia cultural que bajo el proyecto de libertad ejercido en épocas coloniales y contemporáneas se configuran en la consistencia y la valiosa capacidad creativa que en todas las áreas del arte poseen los descendientes de las diversas culturas africanas llegadas a Colombia” (Biblioteca Virtual. Banco de la República, s.f.).
} 
La obra cumbre de Zapata Olivella es Changó, el gran putas publicada en 1983, novela que le tomó veinte años escribir. Pero mientras esto sucedía, hubo otros trabajos que salieron a la luz donde ya se había perfilado la intención de Zapata Olivella de retratar la situación deplorable tanto de los negros como la de los campesinos y trabajadores colombianos, la poca intervención gubernamental para solucionar problemas de índole social y económico y finalmente la presencia de la religión católica como ente supresor y reaccionario dentro de la comunidad. El mismo autor dijo al escribir sobre esos temas: "yo me realizaba a mí mismo en el sentido de retomar todas esas vivencias, de analizarlas, de hacerlas lúcidas como un contexto vivido, como un contexto social en la medida en que lo iba relatando en la novela" (Captain-Hidalgo, 1980,1983: 13). Poco a poco esta vena de protesta social se fue ensanchando hasta incluir sucesos y personajes de varias regiones de Colombia que más tarde formarían la médula de Changó, el gran putas, novela en que culminan las vertientes que habían enriquecido su narrativa anterior.

La riqueza de la obra de Zapata Olivella radica en que cada uno de sus escritos se pueden clasificar en uno o varios géneros: antropológico, sociológico, literario, poético, folclorista, autobiográfico, ensayístico, histórico. Hay un afán pedagógico en sus escritos pues ante todo, y sin ninguna formación formal en la materia, fue un autodidacta de la pedagogía al querer, por medio de sus textos, enseñarle a sus lectores algo, educarlos en ver el mundo afro desde otra perspectiva, la de un humanista que consideraba al negro colombiano y a sus congéneres como cualquier otro ser humano lleno de cualidades pero también con sus defectos, porque él escribió para "el hombre que está explotado y lucha por su libertad a cualquier precio, y ese hombre es el protagonista anónimo que está haciendo la historia universal (los excluidos, los marginados)" (Mina Aragón, 2006: 35).

Por tanto, en muchos de sus textos se puede ver cómo el autor quiso elucidar a su lector respecto a esa ataraxia de la sociedad colombiana respecto de su tratamiento del excluido, del marginado, de cómo las injusticias humanas nunca reciben justicia, al tiempo que muestra la corrupción estatal y eclesiástica. Muchos de sus textos abordan estos temas, como por ejemplo Tierra mojada ${ }^{6}$ (1947) donde la apropiación ilegal de tierras por parte de un terrateniente queda impune debido a la falta de apoyo gubernamental a los afectados. Zapata Olivella supo describir muy bien esa mecánica de apropiación de tierras a sangre y fuego, una forma de usurpar bienes legitimada por la élite colombiana, defendida y apoyada por el estado, muy típica de esa época que lamentablemente continúa sucediendo hoy en día ${ }^{7}$ pero se ha perfeccionado usando figuras legales que dificultan su penalización. Por ende, Tierra mojada forma parte de la nutrida lista de narraciones con las que

\footnotetext{
${ }^{6}$ Esta es la historia de tres familias campesinas que viven en Los Secos, el único pedazo de tierra habitable en la desembocadura del Valle del Río Sinú. Todo el trabajo y el esfuerzo de estas familias están constantemente amenazados por la presencia del gamonal, Jesús Espitia. Tanto el gobierno municipal como el eclesiástico se ven manchados por el ambiente de corrupción producido por Espitia hasta que al final el gamonal se adueña de manera ilegal de Los Secos.

${ }^{7}$ En Colombia el despojo de tierras a la población vulnerable ha sido una práctica muy común desde que se conformó como nación. Siempre se han manejado cifras, pero se puede decir que en la actualidad con la conformación del Centro Nacional de Memoria Histórica se habla de estadísticas y datos más confiables. Es así como según el reporte del Centro el despojo de tierras más significativo fue hecho durante los gobiernos de Andrés Pastrana (1998-2002) y de Álvaro Uribe Velez (2002-2010). Alrededor de 10 millones de hectáreas fueron despojadas ilegalmente de sus verdaderos dueños todo en aras de la política de Seguridad Democrática.
} 
Zapata Olivella denunció situaciones endémicas de la historia colombiana. Como se puede ver no son narraciones solo sobre la cultura y la comunidad afrocolombiana pues es también sobre otro tipo de comunidad que tampoco tienen seguridad, techo, trabajo, razón social, como es la comunidad campesina.

No obstante, hay una historia que encamina la narrativa de este escritor hacia una vena más afín a su siempre intención social, a ese propósito de mostrar al afrocolombiano como "un creador, un pensador, un aportante de imaginarios, de símbolos, de valores y lenguajes" (Mina-Aragón, 2006: 33). Es una vena que devela el lado marxista de Zapata Olivella, y esa historia es Chambacú, corral de negros $^{8}$ (1962). En esta novela la trama gira en torno a la vida de los miembros de una misma familia, a saber, cuatro varones y una mujer -Máximo, Críspulo, José Raquel, "Medialuna” y Clotilde- y la vida en Chambacú. Todos son personajes que "are just as hungry and oppressed as those in $10^{\text {th }}$ Street, but their outlook and sense of historical causality are different" (Lewis, 1987: 102). Es precisamente en esa causalidad histórica donde se encuentra el guiño de Zapata Olivella al pensamiento marxista, que engloba toda esa inquietud social que siempre aquejó al escritor.

Esos trazos marxistas en la obra de Zapata Olivella se dan durante una época en la que todo aquel que tuviera un poco de conciencia social, que estuviera en contra de un sistema que privilegiaba a los poderosos, al culto a lo privado e individual, estaban hermanados por el inconformismo con la situación y de alguna manera querían expresarlo. El marxismo con su instigación por una revolución social se convierte entonces en el credo que mejor apoya un pensamiento igualitario y justo. Chambacú, corral de negros es el texto que de muchas maneras mejor formula la simpatía de Zapata Olivella con el pensamiento marxista y realza su interés por fortalecer su discurso negrista ${ }^{9}$. Por ejemplo, el telón de fondo de muchos de los puntos que usa el personaje principal, Máximo, para abrirle los ojos a sus conciudadanos no es otro que lo establecido en el manifiesto de la Asociación Universal para el Mejoramiento del Negro (Universal Negro Improvement Association -UNIA-). De entre las demandas que se establecen en el manifiesto, hay una en particular que atañe a lo sucedido en Chambacú y esa es "nosotros protestamos en contra de la práctica de reclutar negros y mandarlos a la guerra con fuerzas extranjeras sin el entrenamiento apropiado y demandamos en todos los casos que los soldados negros reciban el mismo entrenamiento que los foráneos ${ }^{10 "}$ (Garvey citado en Van Deburg, 1997: 31). Para Máximo, ver el reclutamiento de los suyos es un volver al pasado infame de la esclavitud, de la guerra de independencia cuando los

\footnotetext{
${ }^{8}$ La historia sucede en 1950 cuando debido a una controvertida decisión del presidente conservador Laureano Gómez, y con la Violencia bipartidista en auge, Colombia fue "el único país latinoamericano que colaboró real y materialmente con la causa norteamericana, para derrotar la expansión del comunismo en Corea, un gran contingente de nacionales combatió contra norcoreanos y chinos en la península" (Meléndez Camargo, 2015: 202).

${ }^{9}$ Ambas ideologías se conjugan en la figura de Máximo cuyo pensar e inconformismo se ven apoyados por una voz narrativa denunciatoria que logran vislumbrar una esperanza por un cambio. Máximo, a diferencia de sus hermanos, se rehusa a enlistarse para la guerra de Corea cuando el ejército llega a Chambacú a reclutar para conformar el batallón Colombia. Para él su lucha de reclamar ayuda gubernamental para proyectos de educación, acueducto y servicios de salud, entre otras necesidades, para Chambacú, es más importante que cumplir el mandato conservador de ir a pelear en una guerra ajena. Es con la llegada después de la guerra de la blanca Inge, la sueca esposa de su hermano José Raquel, que la ideología de Máximo empieza a tener eco en su comunidad porque Inge, convencida de la causa, recluta chambaculeros para formar parte del movimiento de cambio propuesto por Máximo, incentiva a la gente a entrar en pie de lucha y propicia encuentros donde su cuñado pueda difundir su mensaje.

${ }^{10}$ Del original "[w]e protest against the practice of drafting Negroes and sending them to war with alien forces without proper training, and demand in all cases that Negro soldiers be given the same training as the aliens".
} 
negros fueron reclutados para pelear a favor de la corona española para mantener las colonias; es perder el terreno ganado por tantos esclavos cimarrones, es ser vencido sin tener la oportunidad de luchar a cabalidad. Siempre con los preceptos marxistas y del manifiesto de la UNIA ${ }^{11}$ como la base ideológica de esa idea de igualdad social y colectiva, Máximo, con su muerte, empieza a lograr algo: que los chambaculeros se unan en las demandas por la equidad social. No obstante, la última página del libro denuncia el verdadero plan de los inversionistas estadounidenses y del capitán de policía: convertir Chambacú en un complejo turístico. La diferencia en este caso es que la muerte de Máximo simboliza que la hora de pelear ya ha llegado. Como lo dice la frase final del narrador, "[1] dobladora de tabaco podía cerrar los ojos a Máximo con cuatro puntadas de hilo, pues muchos ya los tenían abiertos" (Zapata Olivella, 1982: 155). De ahí que esas enseñanzas sobre la necesidad de tener bienes colectivos, vivir en una sociedad donde el gobierno esté a cargo del ciudadano y sus necesidades, y ser parte de una sociedad inclusiva y proactiva es una manera de pensar que Zapata Olivella continuaría cosechando en sus textos.

De modo que Chambacú, corral de negros es el preludio de una expansión en los temas y géneros que Zapata Olivella va a trabajar posteriormente. Después de esta publicación se puede ver que Zapata Olivella se transforma en un autor aún más vocal y en un activista cultural y social porque, para él, "las circunstancias históricas en que se está viviendo en Latinoamérica en donde cada día es más trágica la existencia de los oprimidos, de los marginados" (Zapata Olivella en Captain-Hidalgo, 1980;1983: 29), son una oportunidad para hacer "eco de esa situación, [y] es tratar con mis libros, con mis artículos, con mis investigaciones de mostrar la existencia de esta injusticia, y a la vez, las aspiraciones culturales, los ideales estéticos, religiosos, etc. de nuestros pueblos" (29).

Estas inquietudes dan paso a distintas narraciones de invaluable valor académico, social, histórico y político pero la condensación de su escribir se da con su obra cumbre Changó, el gran putas (1983), una novela concebida

desde el ángulo de interpretación del negro enfrentado a sus explotadores blancos, mulatos o mestizos. Sin embargo, la visión del negro en América va cambiando de acuerdo con su nueva condición de negro puro, mulato o mestizo. Es decir, que no se trata de una mirada rígida, africana, sino histórica, de acuerdo con las nuevas circunstancias étnicas y culturales que ha sufrido el negro en América. (Zapata Olivella en Captain-Hidalgo, 1980;1983: 30)

Esta novela, de la cual se ha escrito bastante en los medios académicos, particularmente en Estados Unidos, merece que se le reconozca por la historia de la diáspora africana, en su "revalorización mítica de la historia para que sirva de instrumento de lucha para los vivos a partir de la experiencia de los muertos" (30).

\footnotetext{
${ }^{11}$ Cabe mencionar que ese manifiesto Zapata Olivella lo conocía bien no solo porque era un abogado de la causa negrista sino porque en su viaje a Estados Unidos en 1943 había entrado en contacto con varios de los miembros de esta asociación y eventualmente muchos de estos preceptos se vieron reflejados en su obra, fuera por boca de sus personajes o motu proprio cuando escribió ensayos y demás.
} 
Posteriormente a Changó, Zapata Olivella publicó otras narraciones, pero dos de las que mejor muestran el resultado de haber elucubrado por veinte años una novela como Changó son Las claves mágicas de América (1989) y ¡Levántate mulato! Por mi raza hablará el espíritu (1990). Los dos son ensayos que hacen uso de la Historia ${ }^{12}$ americana para establecer una posición política (Las claves) y cultural (¡Levántate!) sobre el trato dado a los negros, indígenas, mulatos y mestizos tanto en el continente americano como en Colombia. Las claves mágicas de América es un escrito que empieza con la desgarradora historia de la población oprimida primero por el colonizador y después por sus descendientes. La introducción y las dos primeras partes establecen el tono de lo que es un texto esclarecedor sobre la Historia que todos deberían conocer. La introducción en sí, "Una Nueva Raza Humana: Los Colonizados y Los hombres sin Almas", desde el título mismo ya va cargada con un significado ideológico que definitivamente se ve apoyado en el resto del texto. Así continúa el resto del escrito, ilustrando lo acaecido tanto a los negros como a los indígenas. Cada uno de los encabezados es incendiario lingüística y semánticamente. Es un análisis profundo y fundamentado en todo aquello que el colonizador, su sistema y su legado le causaron al negro y al indígena. Hay ironía, “[p]odría justificarse, a la manera jesuita, que fueron tantos los males de la colonización americana, que los abusos sexuales quedan implícitos en los atropellos, [...], contra el derecho de gentes, la libertad y la expoliación de los pueblos de América"(Zapata Olivella, 1989: 34); hay reproche "[d]e hecho, aquí en nuestra paradisíaca América, el régimen racista estatuyó a sus anchas, sin sujeción a normas "cristianas", ni "católicas", las prácticas que mejor convenía a los conquistadores y encomenderos para explorar a sus subordinados" (45); hay rabia "[p]ero como la naturaleza humana no puede desconocerse con simples sofismas, resultaba en la práctica que al indio y al negro se les obligaba a obedecer, a hablar el idioma del amo, a trabajar en sus empresas" (44).

Por su parte, ;Levántate, mulato! Por mi raza hablará el espíritu es un ensayo histórico-biográfico-antropológico que "representa la aceptación del autor con su identidad racial personal13" (Tillis, 2005: 86.). En él se vale de la historia de su familia, su ascendencia indígena, negra y española, para hablar de la Historia de Cartagena, de Colombia, del mestizaje que surgió de la mezcla de estas tres culturas. Es un trabajo muy personal e histórico-antropológico que demuestra que Colombia es una nación multiétnica y plural. Su familia es ejemplo de lo que es el país, la mezcla de tres culturas, tres razas, tres idiosincrasias: la indígena, la africana, la española. Este ensayo es un homenaje a su familia y a la Colombia mestiza que muchos desconocen.

Changó catapultó a Zapata Olivella como autoridad en el tema afrodescendiente en Colombia, $\mathrm{y}$, toda una vida de "contar unas injusticias de las cuales yo era víctima y testigo y contra las cuales estoy en franca oposición” (Zapata Olivella en Captain-Hidalgo, 1980;1983: 29), lo cimentó como la voz de una cultura rica en mitología, historia y sociedad. Al igual que en Las claves y iLevántate!, se valida la población marginalizada de Colombia, por ende, estos últimos pueden considerarse como sus manifiestos.

\footnotetext{
${ }^{12}$ Se usa la mayúscula para hacer diferenciación entre las ciencias sociales y la literaria.

${ }^{13}$ Del original "depicts the author's coming to terms with his personal racial identity".
} 
Como se mencionó anteriormente, la obra de Zapata Olivella es basta, trata variados temas y cubre distintos géneros. Su contribución a las letras colombianas, a la historia nacional y local son invaluables. Sus textos rescatan aspectos sociales y culturales tanto de la historia afrodescendiente como de la nacional. Son materiales educativos cuya transversalidad es innegable en cualquier currículo pero en particular para el de la CEA.

\section{La transversalidad de la obra de Zapata Olivella en el currículum de la CEA}

La importancia del currículum para una entidad educativa radica en que es el plan de estudios donde se determinan los objetivos escolares porque "proporciona una descripción de los elementos fundamentales a tener en cuenta en la planificación, organización del plan de estudios y contiene generalmente declaraciones relacionadas con la visión, principios, directrices institucionales, locales, regionales y nacionales de educación” (Jauregui Mora, 2018: 67), además de que "es actualmente el instrumento de transmisión y legitimación del conocimiento en sociedades industriales. Es la expresión y concreción del plan cultural que una institución escolar hace realidad, dentro de determinadas condiciones que matizan ese proyecto educativo" (Ferrini, 1997: 1), haciendo parte vital de la formación de los estudiantes en todos los niveles escolares. La escogencia de qué incluir en el currículum también hace una diferencia en cuanto a lo que se desea enseñar y qué se quiere que los alumnos aprendan porque es una manera de organizar "el plan de estudios en torno a las áreas de aprendizaje fundamentales, en lugar de proporcionar una lista de disciplinas o materias de enseñanza, propone una serie de temas transversales para ser desarrollados a través del plan de estudios" (Jauregui Mora, 2018: 67). Por lo tanto, es en este aspecto donde la transversalidad de contenidos juega un rol primordial cuando se trata de cumplir las directrices locales, regionales y nacionales de las unidades pedagógicas exigidas por cátedras como la de estudios afrocolombianos. La transversalidad denota la cualidad de enmallar elementos y/o conceptos que pueden complementarse entre sí, apoyarse y a la misma vez esta favorece "la utilización de nuevas estrategias, metodologías y necesariamente formas de organización de los contenidos" (Fernández Batanero, 2004: 77). Es en este contexto, en el de la transversalidad de contenido, en el cual la obra de Zapata Olivella puede ser de gran empuje para la CEA porque, por ejemplo, uno de los estándares pedagógicos que define a la CEA es ser "una herramienta para la investigación, el análisis y la reflexión sobre la historia y la problemática de las poblaciones afrodescendientes, y ofrece[r] alternativas pedagógicas para la construcción de una cultura de respeto y valoración de la diversidad étnica y cultural" (Ruiz Cabezas y Medina Rivilla, 2014: 9). Es así como algunos de los textos de Zapata Olivella que cumplen con este parámetro son Las claves mágicas de América y iLevántate mulato! donde se expone sobre la historia de los africanos en Colombia desde su llegada, su adaptación, sus batallas por la libertad y las luchas que hasta el presente libran; o Chambacú, corral de negros donde se muestra la concientización política en una comunidad afrodescendiente de un barrio de invasión. Otro estándar que es vital es el proyectado por el Ministerio de Educación Nacional (MEN) cuando fija orientaciones teóricas y críticas para la 


\section{CEA, donde propone}

[n]uevas lecturas sobre África, los Afroamericanos y los Afrocolombianos, requieren por lo menos en una fase inicial referentes sobre el sentido de los estudios en cuanto a contenidos mínimos, enfoques, consideraciones teóricas y metodológicas que consulten la memoria histórica no sólo de los conquistadores y sus descendientes, sino de los grupos étnicos afros en sus contextos, como protagonistas cuyo verdadero papel histórico ha sido ignorado, tergiversado y menospreciado. Unas lecturas que recojan los resultados de los trabajos y publicaciones de especialistas reconocidos o que se apoyen en rigurosas investigaciones en curso. (MEN en Ibagón Martín, 2015: 28)

El texto de Zapata Olivella que mejor cumple con este lineamento curricular es Changó, el gran putas, la gran epopeya africana donde se da la historia de la diáspora en todo el continente americano. Una narración que cubre de Norteamérica a Suramérica, e incluye pasado, presente y futuro de los africanos. Mitología, lenguaje, creencias, colonialismo, poscolonialismo, racismo, discriminación de y hacia los africanos son parte integral de la historia. Este texto por sí mismo cubre lo que el MEN desea que haga la Cátedra. Sin embargo, no hay recepción de la obra de Zapata Olivella en la CEA.

Por ende, tratar de dar una explicación de la razón por la cual la obra de Zapata Olivella no ha sido usada para fortalecer la CEA puede tener muchas respuestas. Se puede empezar por el hecho de que hay, por parte de los funcionarios educativos, "una visón jerárquica desde la que se da una valoración diferenciada de las normativas curriculares, proceso en el que el marco legal y pedagógico de la CEA, es entendido como inferior frente a otras leyes y disposiciones" (Ibagón Martín, 2015: 16); continuar posiblemente con que "el racismo no ha sido eliminado y aparece encapuchado, [...] mediante los prejuicios, los estereotipos y los estigmas, [que] hacen parte de la cotidianidad" (Gonzáles y Becerra en Ibagón Martín, 2015: 16); sin olvidar que cada secretaría decide qué se enseña, cómo lo implementa y en qué niveles. Además, los recursos para que todos los planteles educativos adopten el mismo currículo no existen, situación que se aúna a la no implementación y a la falta de homogeneidad de esos contenidos curriculares. Un último factor que puede tener incidencia en este hecho es que, si bien Zapata Olivella empezó su carrera como escritor en 1942, no obtuvo notoriedad en los círculos académicos hasta

las décadas de los sesenta, setenta y ochenta, [cuando] a través de académicos norteamericanos en vínculo directo con su propia realidad en materia de blackness, $[. .$.$] algunos escritores comen-$ zaron a ser reunidos en una categoría que incluía lo "afro" (afrocolombianos, afrovenezolanos, afrocostarricenses, etc.) obteniendo, así, una plataforma crítica que los "descubrió", sobre todo en Estados Unidos, en tanto los primeros libros solo fueron publicados allí y en inglés. (Valero, 2016a: 43)

Surge entonces en el ambiente académico colombiano esa nueva categorización de "literatura afrocolombiana", introducida, apoyada, implementada especialmente por críticos estadounidenses, que si bien es "una construcción identitaria establecida confusamente desde un campo intelectual que 
trasladaba el término afro-americano de otros contextos políticos e intelectuales, para referirse a procesos culturales colombianos, tal como lo había hecho la antropología a mediados del siglo XX" (Valero, 2013b: 24), no se populariza por fuera de esos círculos. Nunca fue un autor best seller, fue un escritor para un grupo selecto, leído en un círculo restringido, el de los académicos y conocedores del tema, hecho que no ayuda a convertirse en parte integral de la CEA.

\section{Conclusión}

El programa de la etnoeducación nace como respuesta del gobierno nacional a algunos de los requerimientos que la Ley 115 de 1994 legisló. Dentro del programa de la etnoeducación, como respuesta a la Ley 70 de 1993, se crea la Cátedra de Estudios Afrocolombianos para también cumplir lo legislado y aprovechar lo que el artículo 7 de la constitución estipulaba, esto es, Colombia como una nación pluricultural. De la teoría a la práctica, tanto las leyes como el programa y la cátedra no se han podido implementar a cabalidad. La intención de la etnoeducación de instruir a los estudiantes sobre la historia, cultura y sociedad de las comunidades étnicas colombianas en su concepción apoya la idea de hacer consciente a la población de la pluralidad de la nación, sin embargo, debido a la falta de garantías para su materialización, de estrategias metodológicas y de contenidos uniformes, la implementación tanto del programa como de la cátedra no ha podido ser exitosa. A esta situación se le debe agregar que la falta de visión de muchas secretarías de educación regionales, de cooperatividad entre aquellos que pueden cambiar las limitantes por la que pasa la CEA, hacen el trabajo aun más difícil. El uso de autores que ayuden a fortalecer los contenidos curriculares podría ser una solución, siendo Zapata Olivella el de mejor opción por lo mencionado anteriormente (su universalidad en el tema afrocolombiano, su inclusión de hechos históricos holísticos). Gracias a esto, la transversalidad de la obra de Zapata Olivella es palpable pues en ella se reivindican, entre varios aspectos, los derechos diferenciales de las comunidades étnicas.

Muchos factores se conjugan en la ausencia de la obra de Zapata Olivella en las aulas de clase en todos los niveles educativos. Aparte de los mencionados anteriormente se debe agregar la ataraxia en la que ha caído el proceso de ejecución de la CEA, la diferencia discursiva, social y cultural dentro de la misma comunidad de los afrocolombianos, la falta de visión de muchos programas nacionales de literatura sobre ese discurso articulado (transversal) de la obra de Zapata Olivella que permea la malla curricular de la CEA, para mencionar algunos. Es así que para remediar esta falla se puede hacer uso de las herramientas que el sistema educativo colombiano ofrece con la etnoeducación y la Cátedra de Estudios Afrocolombianos. Otra posibilidad es que el centenario de su nacimiento sea una razón para empezar a hacer un cambio en los ejes educativos. Estos dos factores pueden ser ese empuje para la CEA porque sus textos, o por lo menos algunos apartados de los mismos, si se asumen como parte integral de lecturas obligatorias del pensum educativo, tanto a nivel escolar como universitario, por lo que tratan, como lo presentan y lo que significan para el ideario afrocolombiano, serían un apoyo bienvenido para esta comunidad. 


\section{BIBLIOGRAFÍA}

Biblioteca Virtual. Banco de la República, n.d. Recuperado de http://babel.banrepcultural.org/ cdm/landingpage/collection/p17054coll7

Captain-Hidalgo, Y. (1985). Conversación con el doctor Manuel Zapata Olivella, Bogotá, 1980;1983. Afro-Hispanic Review, 4(1), 26-32.

Cruz Rodríguez, E (2008). La abolición de la esclavitud y la formación de lo público-político en Colombia 1821-1851. Memoria y sociedad, 12, 57-35.

Ferrini, R. (1997). La transversalidad del Currículum. Sinéctica. Revista Electrónica de Educación, 11, 1-9. Recuperado de https://www.redalyc.org/pdf/998/99826037002.pdf

Fernández Batanero, J. M. (2003). La transversalidad curricular en el contexto Universitario. Un puente entre el aprendizaje académico y el aprendizaje natural. Fuentes: Revista de la Facultad de Ciencias de la Educación, (5), 73-86.

Ibagón Martín, N. J. (2015). La cátedra de estudios afrocolombianos: tensiones y Limitantes. Plumilla Educativa, 15(1), 11-22.

Jauregui Mora, S. Z. (2018). La transversalidad curricular: algunas consideraciones para su implementación. Revista Boletín Redipe, 7(11), 65-81.

Lewis, M. A. (1987). Treading the Ebony Path: Ideology and Violence in Contemporary Afro-Colombian Prose Fiction. Columbia: U of Missouri.

Meléndez Camargo, J. D. (2015). Colombia y su participación en la Guerra de Corea: Una reflexión tras 64 años iniciado el conflicto. Historia y memoria, (10), 199-239.

Mina Aragón, W. (2006). Manuel Zapata Olivella: escritor y humanista. Afro-Hispanic Review, 25(1), 25-38.

Colombia Plural (n.d.). Recuperado de https://colombiaplural.com/gran-despojo-tierra-se-dio-losgobiernos-pastrana-uribe/

Palacios Palacios, G. (2018). De rebeldías y revoluciones: perspectivas críticas desde abajo y desde Oriente en el pensamiento de Manuel Zapata Olivella. Estudios de Literatura Colombiana, (42), 117-138. 
Rojas, A. (Ed.). (2008). Cátedra de Estudios Afrocolombianos Aportes para maestros. Popayán: Universidad del Cauca.

Ruiz Cabezas, A. \& Medina Rivilla, A. (2014). Modelo didáctico intercultural en el contexto afrocolombiano: la etnoeducación y la cátedra de estudios afrocolombianos. Indivisa. Boletín de Estudios e Investigación, 14, 6-29.

Tillis, A. (2005). Manuel Zapata Olivella and the "Darkening” of Latin American Literature. Columbia: University of Missouri Press.

Valero, S. (2013). ¿De qué hablamos cuando hablamos de "literatura afrocolombiana"? o los riesgos de las categorizaciones. Estudios de Literatura Colombiana, 32, 15-37.

Valero, S. (2016). La crítica literaria frente a las narrativas afrohispanoamericanas: generalizaciones y racialización. Cuadernos de Literatura, XX(39), 41-52.

VanDeburg, W. (Ed.). (1997). Modern Black Nationalism from Marcus Garvey to Louis Farrakhan. New York: NY: New York U Press.

Zapata Olivella, M. (1989). Las claves mágicas de América. Bogotá: Plaza y Janés.

Zapata Olivella, M. (1982). Chambacú, corral de negros. Medellín: Bedout. 